\title{
Composite Aluminum-Copper Sheet Material by Friction Stir Welding and Cold Rolling
}

S. Kahl and W. Osikowicz

\section{Linköping University Post Print}

\section{Tweet}

N.B.: When citing this work, cite the original article.

Original Publication:

S. Kahl and W. Osikowicz, Composite Aluminum-Copper Sheet Material by Friction Stir Welding and Cold Rolling, 2013, Journal of materials engineering and performance (Print), (22), 8, 2176-2184.

http://dx.doi.org/10.1007/s11665-013-0497-z

Copyright: ASM International

http://www.asminternational.org/

Postprint available at: Linköping University Electronic Press

http://urn.kb.se/resolve?urn=urn:nbn:se:liu:diva-96706 


\title{
Composite Aluminum-Copper Sheet Material by Friction Stir Welding and Cold Rolling
}

\author{
S. Kahl and W. Osikowicz
}

(Submitted August 23, 2012; in revised form January 29, 2013; published online February 14, 2013)

\begin{abstract}
An aluminum alloy and a pure copper material were butt-joined by friction stir welding and subsequently cold rolled. The cold-rolling operation proved to be very advantageous because small voids present after friction stir welding were closed, the interface area per material thickness was enlarged, a thin intermetallic layer was partitioned, and the joint was strengthened by strain hardening. Tensile test specimens fractured in the heat-affected zone in the aluminum material; tensile strengths of the joints exceeded the tensile strengths of the base materials and were as high as $335 \mathrm{MPa}$. During soft annealing of the composite material, a 6-8- $\mu \mathrm{m}$-thick intermetallic layer was grown at the interface. Nevertheless, tensile fracture still occurred in the heat-affected zone of the aluminum material. Electrical resistivity of the joint was smaller than resistivity of the aluminum material. Production of such composite material would result in coiled sheet material that could be subjected to further treatments such as electroplating and forming operations in an efficient and economically viable manner. The new composite material is promising for emerging automotive and industrial electrical applications.
\end{abstract}

Keywords aluminum, cold rolling, copper, electrical resistivity, friction stir welding, tensile strength

\section{Introduction}

Copper and aluminum alloys are the preferred materials for electrical conductors. Recently, interest in joining technologies capable of producing dissimilar aluminum-to-copper joints with good mechanical and electrical properties has strongly increased. This is due to two advantages that aluminum has over copper: The material costs are much lower for aluminum, and aluminum can carry roughly twice as much electrical current per mass unit.

These advantages can be capitalized upon in a number of applications. Two of the main such applications are the-at least partial-replacement of the automotive copper wire harness by aluminum cables (Ref 1) and the-at least partial-replacement of copper leadframes or busbar systems in automotive and industrial systems by aluminum leadframes or busbars. It is expected that in most cases only part of the copper conductors of one system will be replaced by aluminum conductors. For example, a vehicle can have a mixture of electronic control units with aluminum and copper leadframe packages. Therefore, a large increase in the demand for reliable and cost-effective aluminum-to-copper connectors is anticipated.

S. Kahl and W. Osikowicz, Sapa Technology, 61281 Finspong, Sweden; and S. Kahl, Division of Engineering Materials, Department of Management \& Engineering, Linköping University, 58183 Linköping, Sweden. Contact e-mails: soren.kahl@sapagroup.com and wojciech. osikowicz@sapagroup.com.
Another major motivation for the interest in aluminum-tocopper joints is related to future electrical vehicles. If electrical vehicles have to become competitive, then they need to be equipped with batteries that allow for long driving ranges and that can be produced at reasonable costs. Current Li-ion battery concepts require the serial connection of a large number of individual battery cells. Since the two electrodes of a battery cell are based on aluminum and copper foil current collectors, respectively, a large number of aluminum-to-copper joints or connections are required for this application.

In addition to high electrical conductivity, conductor materials need to exhibit good fatigue strength particularly for automotive applications, involving vibrations and varying thermal loads.

Connectors are components where surfaces of two electrically conducting parts are mated in order for the electric current to flow from one part to the other. The mating surfaces are kept together in physical contact by contact forces. For connector materials, the resistance to stress relaxation is an important criterion because extensive stress relaxation corresponds to reduction of the contact force. Low contact forces allow for contact degradation by phenomena such as fretting corrosion (Ref 2, 3).

Automotive connectors often contain spring elements of a different material, for example, steel, such that the contact force is maintained by the spring element while the electric current flows through the copper conductor. This design, however, increases the cost of the connector and is in many cases inappropriate for connectors that are intended to be mated just once and that are not subjected to extremely harsh environments. Many permanent electrical connections in automotive leadframe systems, as well as press-fit pins and insulation displacement connectors, should be made without extra spring elements (Ref 4).

Owing to their low resistance to stress relaxation, aluminum alloys are generally not as good a choice as copper alloys are 
for connector materials (Ref 5-7). Therefore, it makes sense to use copper alloys as connector materials even in systems that mainly use aluminum alloys as conductor materials.

However, joining of aluminum and copper materials is demanding, and it is difficult to design robust processes where these two materials are joined during, for example, production of a leadframe or assembly of an electronic control unit.

A composite material where aluminum and copper sheets have been butt-joined along an interface of high mechanical strength and low electrical resistivity could eliminate the need to join aluminum to copper during the assembly of products. For using such a composite aluminum-copper sheet material, only aluminum-to-aluminum and copper-to-copper joints would be required.

Ultrasonic welding is an extremely versatile technique that has been used to join dissimilar materials (Ref 8). This technique has been successfully applied to join aluminum to copper, but the process window is smaller, and thus the process is less robust than for joining of aluminum to aluminum and copper to copper.

Connectors are often manufactured from coiled sheet material since this allows for an effective use of the forming and stamping devices commonly used. Connector materials are usually plated with a different material in the contact zone. Copper and aluminum are often coated by thin layers of other metals (Ref 2, 3, 9) to reduce the contact resistance and the mating force, and to increase the connector lifetime. Common processes, such as electroplating, are preferably run in continuous mode on coiled sheet material.

For the applications discussed above, the composite material should be available as coiled sheet material with smooth surfaces and in thicknesses range between approximately 0.01 and $1 \mathrm{~mm}$. We recently proposed a method for making such composite material (Ref 10) and performed a feasibility study that used the techniques of friction stir welding (FSW) and subsequent cold rolling. The results of the feasibility study are presented in this article.

FSW is a promising technology for joining copper and aluminum alloys. As reported by others and confirmed by us, though, it appears impossible to obtain strong welds when the welding tool follows the butt line; the low mechanical strength could be attributed either to defects such as voids or to the detrimental effect of large intermetallic particles or regions (Ref 11-15). An alternative approach is to offset the welding tool completely or partially into the aluminum or copper alloy to avoid formation of volumetric flaws and of excessive volume of intermetallic compounds by unnecessary mixing (Ref 11, 1418). Special weld geometries including steps and recesses machined into faying surfaces also yielded good welds (Ref 19). A recent study concluded that it was still impossible to obtain acceptable mechanical properties of aluminum-tocopper joints by FSW alone, at least within the process parameter space covered in that investigation (Ref 14).

In the literature, there is no agreement on the type of FSW process that yields the best mechanical properties for welding of aluminum and copper materials. Besides, only part of the publications have reported any tensile test values although many standards and regulations are based on the tensile strength measured on specimens extracted perpendicularly to the weld line. Liu et al. (Ref 15) reported a tensile strength of $127 \mathrm{MPa}$ for FS welds of AA5082-O to pure copper. Xue et al. (Ref 16) obtained $110 \mathrm{MPa}$ of tensile strength for welds between AA1060 and commercially pure copper; failure
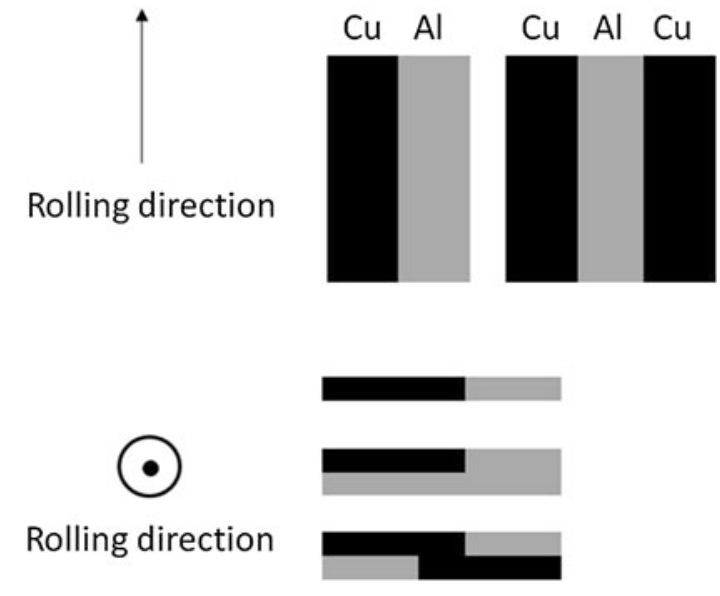

Fig. 1 Possible extensions of the basic idea to join copper to aluminum by friction stir welding and subsequent rolling

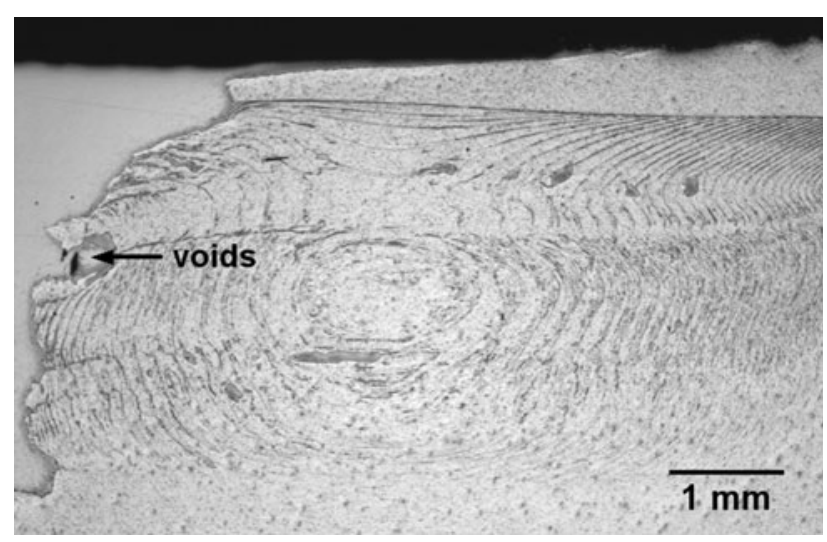

Fig. 2 Optical image of the cross section of the friction stir weld between AA6063-T6 and soft-annealed DHP copper before cold rolling. Voids are indicated by the arrow

occurred in the heat-affected zone of the aluminum material, which indicated a very good FS weld quality. These authors also reported very good bendability. Pietras had already previously observed that the highest tensile strength occurred when the specimens fractured in the heat-affected zone of the weld; he reported maximum tensile strength values of $85 \mathrm{MPa}$ for FS welds between AA1050 and pure copper (Ref 19). Savolainen et al. (Ref 18) obtained up to $150 \mathrm{MPa}$ in tensile strength for FS welds between AA6061-T6 and cold-rolled pure OF-copper.

Large intermetallic particles and voids will also be detrimental to fatigue strength. We recently investigated the effect of voids on the fatigue strength of FS welds in AA6061-T6 and found that small voids that extend over $10 \%$ of the weld thickness reduced the fatigue strength by approximately $20 \%$, while the tensile strength was only reduced by approximately $10 \%$ (Ref 20). It is worth emphasizing, though, that flaw-free FS welds in aluminum possess very high fatigue strength (Ref 20-22).

For electrical applications, it is imperative that the weld region does not significantly increase the electrical resistance of the composite material. As shown elsewhere, increased heat input during FSW was found to increase the electrical resistance of the weld (Ref 23). 



Fig. 3 Cross section images by light optical microscopy. The dark material is copper. (a) Friction stir welded interface after cold rolling to (a) $0.86 \mathrm{~mm}$ and (b) $0.28 \mathrm{~mm}$, (c) magnified view of the weld zone after cold rolling to 0.28 -mm thickness, (d) intermetallic layer formed during annealing at $350{ }^{\circ} \mathrm{C}$

Besides the still prevailing problems regarding the mechanical properties of the aluminum-to-copper FS welds, it is also for other reasons unrealistic to manufacture the above envisioned composite aluminum-copper sheet material in industrial scale using only FSW: The process costs per length of joint for FSW of aluminum to copper are too high and the weld surfaces are not smooth such that it appears impossible to obtain highquality coiled sheet material as it is required for the manufacture of connectors.

Aluminum-copper composite components may also be used for devices based on heat conduction. In cooling of electronics, for example, cooling of separate high-power integrated circuits, an aluminum-copper composite material could be applied. Copper material would then be in contact with the integrated circuit and aluminum material would be joined to a heat sink, for example, a metal housing. Thus, the high heat conductivity of copper would be favorably combined with the low mass density of aluminum.

For certain applications, it may be desirable to obtain a composite conductive material comprising two or more layers of metallic materials on top of each other. The method of manufacturing may thus include to FS weld several aluminumcopper plates together, to stack the welded plates, and to subsequently bond the plates during rolling. Such variants could include those depicted schematically in Fig. 1.

Stacking of several welded plates prior to rolling is also a possibility to compensate for the rather limited maximum thickness of the plates that can be FS welded: common rolling ingots have thickness of several decimeters, while common maximum thicknesses of FS welds are in the centimeter range. For high total rolling reductions, the roll formability of the composite material may be exceeded and intermediate annealing steps will become necessary. Also hot rolling followed by cold rolling could be considered to increase the total possible rolling reduction.

In the investigation presented here, we demonstrated the feasibility to produce a single-layer composite aluminumcopper sheet material using laboratory equipment.

\section{Material and Experimental Procedure}

In the first step, aluminum and copper plates were FS welded in laboratory scale. The FSW process had not been fully optimized for the material used in the present investigation and was carried out on a retrofitted 5-axes milling machine. Aluminum alloy AA6063-T6 and soft-annealed DHP copper were welded in butt joint configuration, with the following welding parameters: Feed rate per tool revolution of $0.1 \mathrm{~mm} /$ revolution, angular tool velocity of $1000 \mathrm{rpm}$, and tool inclination angle of $2.5^{\circ}$. The employed tool was of the Triflute type and had a shoulder diameter of $18 \mathrm{~mm}$ and a probe diameter of $6 \mathrm{~mm}$. The aluminum material was placed on the advancing side and the tool center was offset $2.5 \mathrm{~mm}$ into the aluminum material.

A 3.20-mm-thick, 120-mm-long, and 80-mm-wide cuboid was milled out from a welded sample and cold-rolled to 0.28 mm final thickness.

Cold rolling was performed on a laboratory cold-rolling mill with the following sequence of rolling steps: $3.10,2.87,2.48,2.02$, $1.59,1.18,0.85,0.64,0.52,0.44,0.40,0.37,0.34,0.32,0.31$, and $0.28 \mathrm{~mm}$, where the measurement error was $\pm 0.02 \mathrm{~mm}$. The roll gap was closed for all rolling steps subsequent to $0.85-\mathrm{mm}$ material thickness, no front or back tension was applied, and the sheet was fed manually into the roll gap.

Vickers hardness was measured with a load of $50 \mathrm{~g}$. Hardness profiles were measured at mid-thickness across the weld.

Tensile tests on composite material were performed on specimens taken out perpendicular to the weld line. Specimen widths were $12.5 \mathrm{~mm}$ for FS welded material and 10 and $5 \mathrm{~mm}$ for FS welded and cold-rolled material. While the gauge length for FS welded material was $50 \mathrm{~mm}$, it was reduced to $20 \mathrm{~mm}$ for FS welded and cold-rolled material. Since the cold-rolled material only was $120 \mathrm{~mm}$ wide, we did not take out specimens of standard size.

Optical images were taken in a Zeiss optical microscope. For electron optical imaging, we used an FEI scanning electron microscope with field emission gun. For concentration analysis 

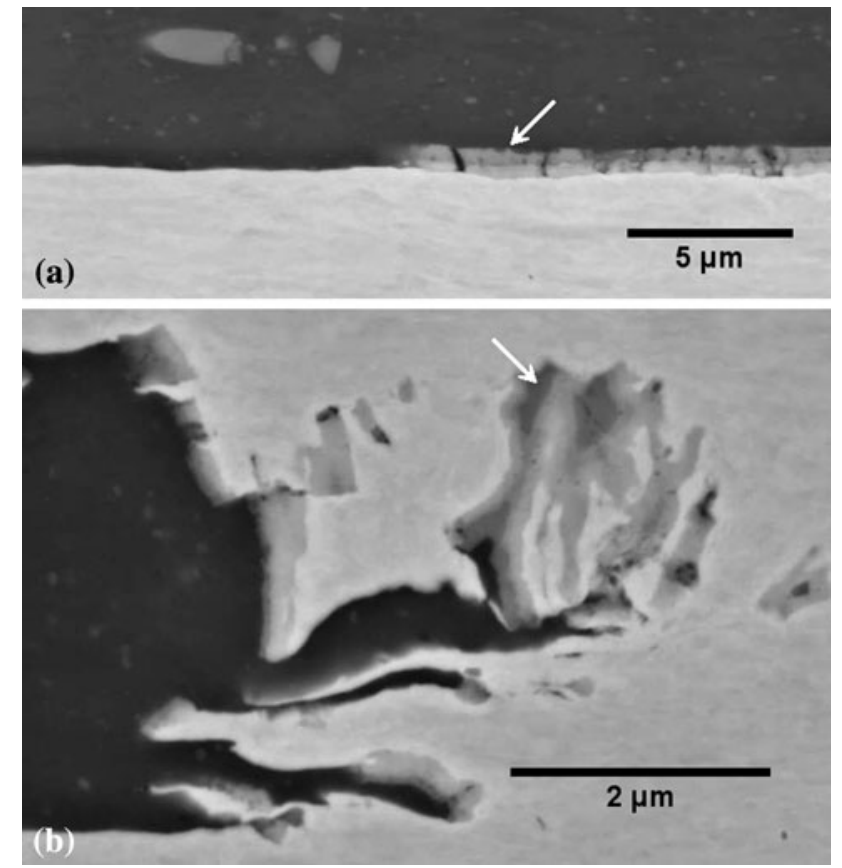

Fig. 4 Backscattered electron images of the joint cross section after cold rolling to $0.28-\mathrm{mm}$ thickness. The dark material is aluminum. (a) Straight interface region including fractured thin intermetallic film, indicated by arrow. (b) Intermetallic material trapped in a "pocket" of the interface, indicated by arrow

by energy dispersive x-ray fluorescence spectroscopy (EDX), we only considered the aluminum and copper signals.

Averaged electrical resistivity was determined for 5-mmlong sections, along a strip of 5-mm width that had been taken out perpendicular to the weld line. The procedure was the following. Electrical resistance was measured with the fourprobe method at $1 \mathrm{~A}$ measurement current. Three of the four measurement probes were fixed to the ends of the strip while the fourth probe, measuring voltage drop, was moved in steps of $5 \mathrm{~mm}$ along the strip. Five voltage measurements were carried out at each position. The resistance measured at the first position was subtracted as offset from all subsequent resistance values. Local widths of the strip and exact positions of the voltage measurements where determined in an optical measurement microscope, and local thicknesses were determined by an inductive thickness probe. The errors were calculated from the measurement errors of electrical resistance and strip cross section.

\section{Results and Discussion}

The FS welded material used for this investigation contained small voids that extended over up to $5 \%$ of the weld thickness, as shown in Fig. 2.

Figure 3(a)-(c) depict the cross sections after cold rolling with approximately 70 and $90 \%$ thickness reduction. The voids were fully closed during cold rolling. The interface area between aluminum and copper was large in relation to the material thickness because rolling reduced the material thickness much more than it reduced the interface area.

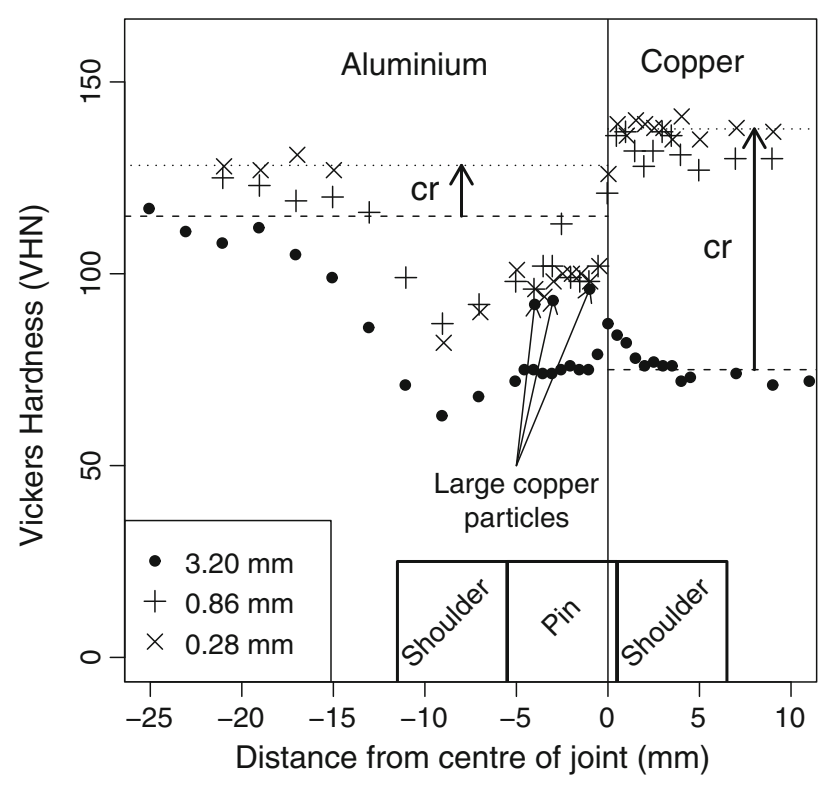

Fig. 5 Hardness profiles across friction stir weld for 3.20-mm-thick material and after cold rolling from $3.20 \mathrm{~mm}$ to indicated thicknesses. Lines show hardness values far away from the joint: dashed lines represent hardness before cold rolling, dotted lines after cold rolling to $0.28-\mathrm{mm}$ thickness. The vertical arrows indicate strain hardening during cold rolling (cr). The positions of pin and shoulder of the welding tool are indicated in the bottom part of the figure

It is a geometrical effect that a large interface area per material thickness improves the robustness of the joint against possible unfavorable mechanical and electrical properties of the interface. Such unfavorable properties are often related to intermetallic layers that may form at elevated temperatures or under high electric currents. This issue will be discussed further below in this section.

In the light optical images, an intermetallic layer between the copper and aluminum materials could only be observed after annealing, as shown in Fig. 3(d). Electron optical images acquired with backscattered electrons revealed that a thin intermetallic interlayer already existed after cold rolling, though. This layer consisted of at least two different intermetallic phases, visible in Fig. 4(a). The intermetallic layer had obviously been fractured during cold rolling such that metallic binding between copper and aluminum prevailed over large parts of the interface. Figure 4(b) depicts intermetallic material that was trapped in the "pockets" of the aluminum-to-copper interface.

The presence of a double intermetallic layer after FSW had previously been reported by other investigators. Two intermetallic layers of $\mathrm{Al}_{2} \mathrm{Cu}$ and $\mathrm{Al}_{4} \mathrm{Cu}_{9}$ with 63 and 33 at.\% aluminum concentration and a total thickness of $200 \mathrm{~nm}$ were observed when the welding tool was placed completely inside the aluminum material (Ref 17). Also when the welding tool was only partially offset into the aluminum alloy, two intermetallic layers of the same phases were observed, but in the case of a total thickness of $1 \mu \mathrm{m}$ (Ref 16). $\mathrm{Al}_{2} \mathrm{Cu}$ and $\mathrm{Al}_{4} \mathrm{Cu}_{9}$ were also the most commonly observed phases in the mechanically intermixed regions of joints that were FS welded with no or only a slight tool offset (Ref 13-15, 24). In three of these investigations, also the $\mathrm{Al}-\mathrm{Cu}$ intermetallic phase was detected (Ref 13, 15, 24), and one publication reported the observation of the $\mathrm{AlCu}_{3}$ phase (Ref 15). 
The surface of the composite material exhibited a rather clean and straight line of separation between the copper and aluminum materials. The line of separation on the opposite surface of the material was shifted by more than $1 \mathrm{~mm}$ with respect to the line on the first surface. In all cases, the solid copper extended further into the aluminum alloy on the weld face side than on the weld root side. The line of separation was more well defined on the root side of the weld, particularly prior to cold rolling. In the following, we will refer to the line of separation on the root side as "center of joint" and present our data with reference to this line.

Vickers hardness was measured on 3.20-mm-thick material after FSW and on 0.86 and 0.28 -mm-thick materials after cold rolling. The corresponding three hardness profiles, measured at mid-thickness across the weld, are shown in Fig. 5.

The softened zone on the aluminum side extended further than $10 \mathrm{~mm}$ from the center of joint. In the region that was occupied by the pin of the welding tool during welding, i.e. in the weld nugget, the hardness of the aluminum material was rather constant and exceeded the aluminum hardness in the region below the shoulder of the welding tool, i.e. in the heataffected zone. The hardness in the heat-affected zone of FS welded heat-treatable aluminum alloys is usually lower than in the weld nugget because precipitate coarsening dominates in the heat-affected zone while precipitate dissolution followed by natural ageing leads to some recovery of strength in the weld nugget (Ref 25).

A few measurements for the 3.20 -mm-thick material were deliberately made on large copper particles in the aluminum side. Their hardness exceeded the hardness of the soft-annealed copper matrix.

DHP copper was softer than aluminum AA6063-T6 before cold rolling. However, due to the high strain hardening in copper during cold rolling, the copper sides of the strips exhibited higher hardness after cold rolling than the aluminum sides. The distances between the dashed and dotted lines in Fig. 5 represent the hardness increases in the two materials during cold rolling with approximately $90 \%$ reduction in thickness and are based on hardness measurements far away from the weld. The increase in hardness of the aluminum material in the weld region by approximately $25 \mathrm{VHN}$ or $35 \%$ was stronger than the hardness increase far away from the weld.

Tensile strengths are given in Table 1. After FSW, the composite material possessed $169 \mathrm{MPa}$ of tensile strength, which is high as compared to the previously reported values given in the introduction of this article. Besides FSW process parameters, base material properties can have a significant influence on weld strength.

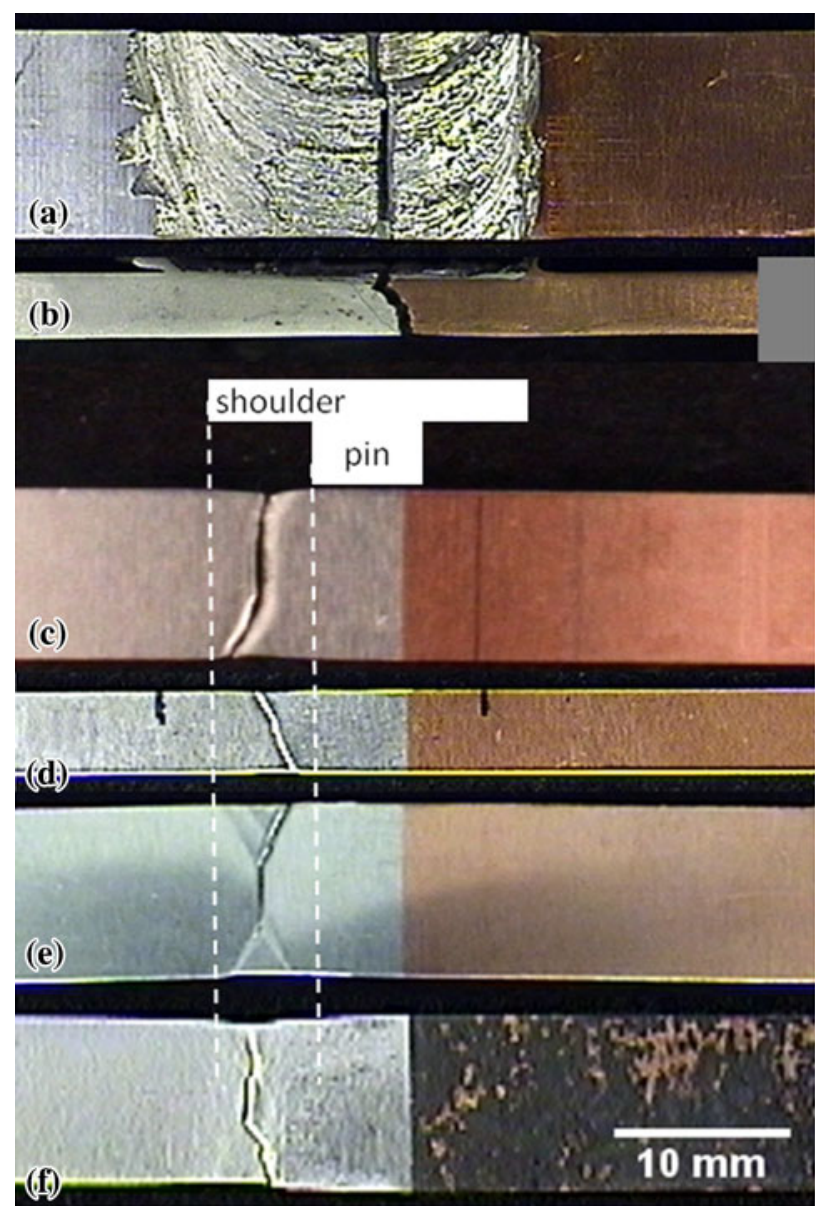

Fig. 6 Tensile test specimens after fracture. (a) and (b) Top and side views of aluminum-copper composite material after FSW, respectively; (c) aluminum-copper strip cold rolled to $0.86-\mathrm{mm}$ thickness, and 10-mm width; (d) and (e) aluminum-copper strip cold rolled to $0.28-\mathrm{mm}$ thickness, and of $5-\mathrm{mm}$ and $10-\mathrm{mm}$ widths; and (f) aluminum-copper strip cold rolled to $0.28-\mathrm{mm}$ thickness and soft annealed, $10-\mathrm{mm}$ width. The approximate position of the welding tool is indicated in the figure

After cold rolling, the composite material exhibited a significantly higher tensile strength than each of the base materials in their original temper prior to cold rolling. The higher cold-rolling reduction of the 0.28 -mm-thick composite material as compared to the 0.86 -mm-thick composite material was reflected by an approximately $10 \%$ higher tensile strength. 


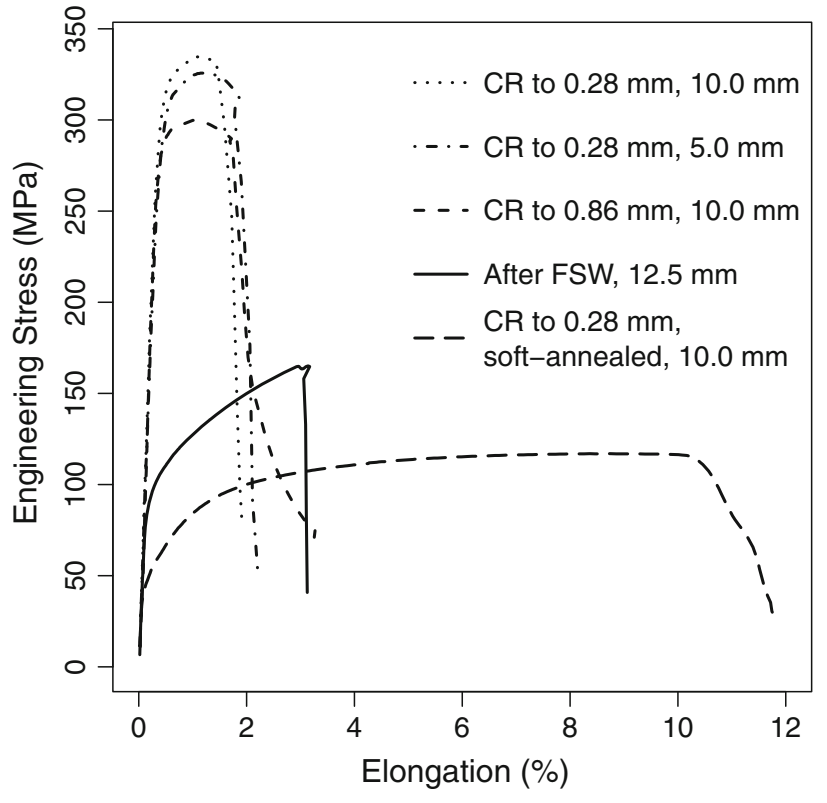

Fig. 7 Tensile test curves of specimens of different widths taken from FS-welded aluminum-copper material before and after cold rolling to $0.28-\mathrm{mm}$ thickness and before and after soft-annealing at $350{ }^{\circ} \mathrm{C}$. Specimen widths as well as thicknesses after cold rolling (cr) are given in the legend

Tensile test specimens taken from composite material after FSW fractured at the interface between the copper and aluminum materials, while specimens taken from composite material after FSW and cold rolling fractured in the heat-affected zone of the aluminum material, which are shown in Fig. 6. The location of fracture shifted because voids were fully consolidated and the intermetallic layer was partitioned during cold rolling.

To the best of our knowledge, all previously reported tensile strength values of aluminum-to-copper joints after FSW were well below the original tensile strengths of the base materials. With our new process route, on the other hand, we demonstrated that it is possible to exceed the original tensile strength of the base materials by almost $50 \%$.

Tensile strength is not as local a measure of strength as micro hardness is. The tensile strength measured in the tensile test is determined by the onset of diffuse necking which usually extends over a region that is approximately as long as the specimen is wide (Ref 26). If only the minimum hardness values were considered, it would be surprising that the tensile strengths of the composite materials after cold rolling were significantly higher than the tensile strength of the aluminum base material before cold rolling. The region where measured hardness values of the composite materials were lower than in the base materials extended around $13 \mathrm{~mm}$ from the center of joint into the aluminum material. However, the zone on the aluminum side that contained copper particles extended over more than $7 \mathrm{~mm}$, where the density of copper particles was the highest within the first $5 \mathrm{~mm}$, as can be seen from Fig. 3(a) and (b). Therefore, we suggest that a constraint effect increased the tensile strength measured on the specimens.

This suggestion is supported by Fig. 6(c) and (e) which show that necking is indeed limited to a small region below the shoulder of the welding tool. Localized, through-thickness necking in homogeneous material usually occurs along lines

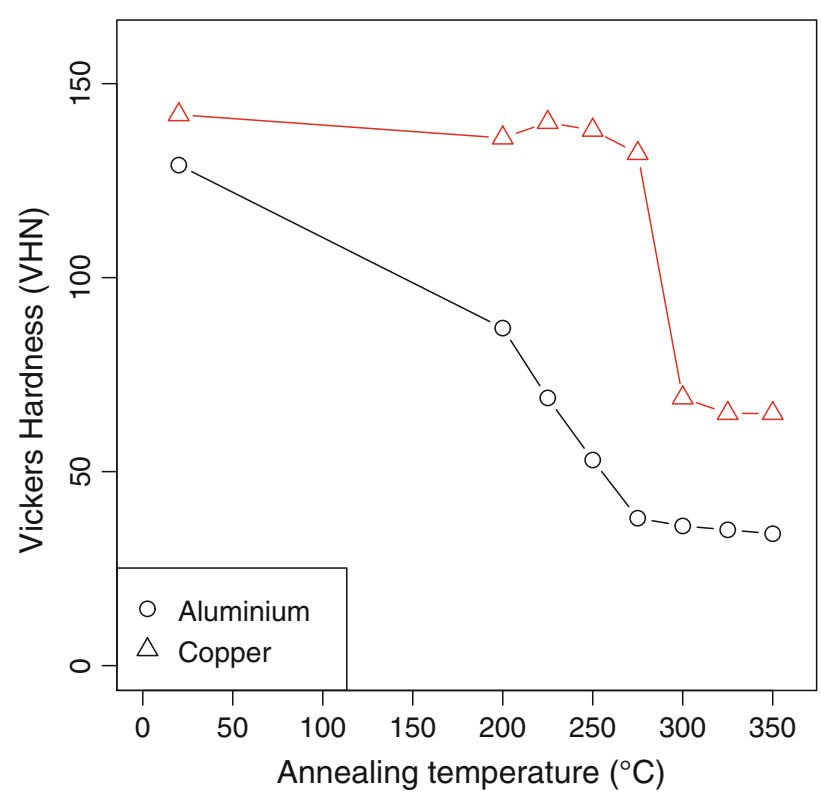

Fig. 8 Hardness reductions during annealing of the base materials after cold rolling from 3.20 - to $0.28-\mathrm{mm}$ thickness

inclined at angles of $30^{\circ}-60^{\circ}$ to the specimen edge. For the composite materials after cold rolling, however, the center parts of these lines were perpendicular to the specimen edges. We believe that diffuse necking of the soft heat-affected zones in the aluminum material was hindered by the surrounding hard regions of the specimens, the weld nugget, and the base material. Therefore, the soft material was allowed to strain harden much more than it would have done in a tensile test of a uniform specimen that consisted only of the soft material.

In agreement with our above suggestion, a specimen of 5-mm width exhibited lower strength and higher ductility than a specimen of 10-mm width, where both of them were taken from the composite material after cold rolling to $0.28 \mathrm{~mm}$. Tensile test curves of these two specimens have been plotted in Fig. 7 together with the tensile test curves of other weld specimens. We would like to point out that tensile test curves of weld specimens should be analyzed with care since they contradict one of the basic ideas of the tensile test-namely that the mechanical properties of the material should be uniform over the region from which the specimen is taken.

Also from inspection of Fig. 6(d) and (e), it appears that the constraint effect was less severe for the 5-mm-wide specimen than for the $10-\mathrm{mm}$-wide specimen. This should be the case since a high ratio of specimen width to length of the soft region should correspond to a strong constraint effect. Constraint effects had already been considered as explanation of the mechanical properties of the softest region of a FS weld in AA2024-T6 (Ref 27). An overview over the literature related to the constraint effect in welded HSLA steel has been given in reference (Ref 28).

The behavior of the aluminum-to-copper interface during heat treatment is of interest for at least two reasons. First, a soft annealing step after some degree of cold rolling would increase the total allowed degree of rolling reduction. Second, in several applications, the interface would be subjected to elevated temperatures and high electrical currents during operation. In this article, we describe the effect of soft annealing on interface structure and tensile properties of the composite material. 



Fig. 9 Backscattered electron images of the cross section after cold rolling to $0.28-\mathrm{mm}$ thickness and annealing for $2 \mathrm{~h}$ at $350{ }^{\circ} \mathrm{C}$. The dark material is aluminum. (a) Interface region with four different layers, indicated by dashed lines. (b) Concentration profile by EDX over the four phases (P1 to P4) of the interlayer. Numbers behind the arrows indicate average concentrations in at $\%$ over data points measured in the center of the respective intermetallic layer. (c) Copper particles of different sizes within the aluminum matrix

Base material cold rolled to $0.28 \mathrm{~mm}$ was annealed to different temperatures. Heating and cooling rates were $50{ }^{\circ} \mathrm{C} / \mathrm{h}$ and the dwell time at maximum temperature was $2 \mathrm{~h}$. The resulting softening curves of both the aluminum and copper materials are depicted in Fig. 8.

$350{ }^{\circ} \mathrm{C}$ was chosen as temperature for soft annealing of the composite material in $0.28-\mathrm{mm}$ thickness. This heat treatment resulted in the formation of a continuous intermetallic layer at



Fig. 10 Electrical resistivity of the aluminum-copper strip cold rolled to 0.28 -mm thickness. The resistivity is given for 5-mm-long intervals, along a strip of $5-\mathrm{mm}$ width that was extracted perpendicular to the weld line

the interface between aluminum and copper. The width of the intermetallic layer in the straight sections of the interface varied between 6 and $8 \mu \mathrm{m}$, as shown in Fig. 3(d).

Four different layers were revealed in the images obtained by backscattered electrons, shown in Fig. 9. Phase P4 that formed closest to the pure copper material is suggestive of a layer where aluminum is in solid solution in the copper matrix. Average aluminum concentrations measured in the centers of the other three phases, P1-P3, are given in Fig. 9(b). These concentrations do not correspond closely to the concentrations of the intermetallic phases in the binary aluminum-copper phase diagram.

Interlayer formation was also observed around copper particles embedded in the aluminum matrix. Figure 9(c) shows that the degree of transformation and the number of intermetallic phases formed depended on the size of the copper particles.

Braunovic and Aleksandrov investigated the interfaces of samples taken from a FS-welded aluminum-copper bar after annealing for different times at different temperatures (Ref 29). They observed the formation of five different intermetallic phases that do not generally agree with the phases commonly observed directly after FSW (Ref 13-17, 24). After 5-h annealing at $380^{\circ} \mathrm{C}$, a total interlayer thickness of $8.6 \mu \mathrm{m}$ was reported - this was in the same range as the double layer thickness observed by us. Braunovic and Aleksandrov stated that electrical and mechanical properties rapidly degraded when a thickness threshold value of $2 \mu \mathrm{m}$ was exceeded. Abbasi et al. (Ref 30) arrived at a similar conclusion with respect to the influence of interlayer thickness on mechanical properties of the interface: For roll-bonded aluminum-copper bimetal sheet they observed a strong decrease in the peeling force when an interlayer thickness of $2.5 \mu \mathrm{m}$ was exceeded. While the interlayer thickness in our feasibility study reached 6-8 $\mu \mathrm{m}$ 
after soft-annealing, the interlayer would be broken up and dispersed during subsequent cold rolling steps.

Our soft-annealed composite material possessed a low tensile strength as presented in Table 1 and Fig. 7, but the intermetallic layer did not adversely affect the material's strength even after annealing: as shown in Fig. 6(f), the tensile fracture still occurred within the heat-affected zone, at the same position as before the soft annealing.

Electrical resistivity is displayed as a function of distance to the first measurement position in Fig. 10.

The electrical resistivity of AA6063-T6 was almost twice as high as that of DHP copper after cold rolling to $0.28 \mathrm{~mm}$. In the joint region, the electrical resistivity reached a value in between those of the two base materials. This means that the resistance of the strip was dominated by the resistance of the aluminum material.

The variations in measured resistivity in the aluminum material were significant with respect to the measurement error. After the cold-rolling reduction in excess of $90 \%$, the AA6063T6 aluminum alloy, which is material in the peak-aged state, exhibited first signs of surface cracks. We believe that this can account for the observed variations in resistivity.

\section{Conclusions}

We presented the results of a feasibility study where we combined the FSW and cold-rolling processes to produce a composite aluminum-copper material. While many investigations have looked into FSW of aluminum to copper, the combination of FSW with subsequent cold rolling is new and has significant advantages over FSW alone.

Cold rolling consolidated the FS weld and increased the ratio of interface area to material thickness. The intermetallic layer formed during FSW was partitioned during cold rolling such that only part of the aluminum-to-copper interface consisted of an intermetallic layer. Therefore, the combined process is more robust than FSW alone. Cold rolling introduced strain hardening into the composite material so that the mechanical strengths of our joints by far exceeded those of previously reported aluminum-to-copper joints made by FSW. The total length of the composite material is multiplied by cold rolling, which makes the combined process of FSW and cold rolling more economic than FSW alone.

In addition to the excellent mechanical properties, the electrical resistance of the joint after FSW and cold rolling was very low.

\section{Acknowledgments}

The authors gratefully acknowledge significant contributions from our colleagues at Sapa Technology: O. Karlsson, S. Nilsson, C. Widlund, and H. Carlsson carried out laboratory work, and S. Zajac performed the electron optical analysis. This project was supported by the Sapa Group research program on Application Technology.

\section{References}

1. S. Koch and H. Antrekowitsch, Aluminum Alloys for Wire Harnesses in Automotive Engineering, Berg und Huttenmannische Monatshefte, 2007, 152(2-3), p 62-67
2. E. Vinaricky, Elektrische Kontakte, Springer, Berlin, 2002

3. P. Slade, Electrical Contacts: Principles and Applications Electrical Engineering and Electronics, Marcel Dekker, New York, 1999

4. S. Kahl, Cold Joining of Electrical Contacts, 1. Symposium Connectors (Lemgo, Germany), 2006

5. M. Braunovic and IEEE. Stress Relaxation of Aluminum Wire Conductors, Proceedings of the Forty-Fourth IEEE Holm Conference on Electrical Contacts, 1998

6. B. Wiltshire, Stress-relaxation Measurements of Aluminum Conductors in Insulation Displacement Connectors (IDCs) and Related Effects on Contact Resistance, IEEE Trans. Compon. Hybrids Manuf. Technol., 1984, 7(1), p 11-19

7. H.-A. Kuhn, I. Altenberger, A. Käufler, H. Hölzl, and M. Fünfer, Properties of High Performance Alloys for Electromechanical Connectors, Copper Alloys-Early Applications and Current Performance-Enhancing Processes, L. Collini, Ed., 2012. p 52-68

8. G. Wagner, F. Balle, and D. Eifler, Ultrasonic Welding of Hybrid Joints, JOM, 2012, 64(3), p 401-406

9. R. Schneider, H. Löbl, S. Großmann, T. Schoenemann, and M. Holdis, Langzeitverhalten von Aluminium-Kupfer-Verbindungen in der Elektroenergietechnik, Metall-Forschung, 2009, 11, p 591-594

10. S. Kahl, Composite Conductive Component and Method for Making It, PCT/SE2010/051335, World Intellectual Property Organization, Sapa AB, Sweden, 2011

11. W.B. Lee and S.B. Jung, Void Free Friction Stir Weld Zone of the Dissimilar 6061 Aluminum and Copper Joint by Shifting the Tool Insertion Location, Mater. Res. Innov., 2004, 8(2), p 93-96

12. L.E. Murr, Y. Li, R.D. Flores, E.A. Trillo, and J.C. McClure, Intercalation Vortices and Related Microstructural Features in the Friction-Stir Welding of Dissimilar Metals, Mater. Res. Innov., 1998, 2(3), p 150-163

13. J.H. Ouyang, E. Yarrapareddy, and R. Kovacevic, Microstructural Evolution in the Friction Stir Welded 6061 Aluminum Alloy (T6-temper condition) to Copper, J. Mater. Process. Technol., 2006, 172(1), p 110-122

14. I. Galvão, A. Loureiro, D. Verdera, D. Gesto, and D. Rodrigues, Influence of Tool Offsetting on the Structure and Morphology of Dissimilar Aluminum to Copper Friction-Stir Welds, Metall. Mater. Trans. A, 2012, p 1-10

15. H.J. Liu, J.J. Shen, L. Zhou, Y.Q. Zhao, C. Liu, and L.Y. Kuang, Microstructural characterisation and mechanical properties of friction stir welded joints of aluminium alloy to copper, Sci. Technol. Weld. Join., 2011, 16(1), p 92-98

16. P. Xue, B.L. Xiao, D.R. Ni, and Z.Y. Ma, Enhanced Mechanical Properties of Friction Stir Welded Dissimilar Al-Cu Joint by Intermetallic Compounds, Mater. Sci. Eng. A., Struct. Mater., 2010, 527(2122), p 5723-5727

17. C. Genevois, M. Girard, B. Huneau, X. Sauvage, and G. Racineux, Interfacial Reaction during Friction Stir Welding of $\mathrm{Al}$ and $\mathrm{Cu}$, Metall. Mater. Trans. A Phys. Metall. Mater. Sci., 2011, 42A(8), p 2290-2295

18. K. Savolainen and J. Mononen, A Preliminary Study of Friction Stir Welding of Dissimilar Metal Joints of Copper and Aluminium, 6th International Friction Stir Welding Symposium, Saint-Sauveur, Canada, 2006

19. A. Pietras, Friction Stir Welding of Aluminium to Copper, Weld. World, 2005, 49(9), p 122-133

20. S. Kahl, The Influence of Small Voids on the Fatigue Strength of Friction Stir Welds in the Aluminium Alloy AA6061-T6, Heron, 2010, 55(3-4)

21. S. Kahl, Fatigue Strength of Friction Stir Welds in Aluminium Alloy AA6082-T6, TWI Friction Stir Welding Symposium (Timmendorfer Strand, Germany), 2010

22. J. Mendoza and S. Kahl. Fatigue and Tensile Properties of Friction Stir Welds in AA6061-T6 and AA6082-T6 from Production Trials, TWI FSW Symposium (Huntsville, USA), 2012

23. E.T. Akinlabi, D.M. Madyira, and S.A. Akinlabi, Effect of Heat Input on the Electrical Resistivity of Dissimilar Friction Stir Welded Joints of Aluminium and Copper, IEEE Africon, 2011

24. I. Galvao, J.C. Oliveira, A. Loureiro, and D.M. Rodrigues, Formation and Distribution of Brittle Structures in Friction Stir Welding of Aluminium and Copper: Influence of Process Parameters, Sci. Technol. Weld. Join., 2011, 16(8), p 681-689

25. P.L. Threadgill, A.J. Leonard, H.R. Shercliff, and P.J. Withers, Friction Stir Welding of Aluminium Alloys, Int. Mater. Rev., 2009, 54(2), p 49-93

26. W.F. Hosford and J.L. Duncan, Sheet Metal Forming: A Review, J. Metals, 1999, 51(11), p 39-44 
27. C. Genevois, A. Deschamps, and P. Vacher, Comparative Study on Local and Global Mechanical Properties of 2024 T351, 2024 T6 and 5251 O Friction Stir Welds, Mater. Sci. Eng. A Struct. Mater., 2006, 415(1-2), p 162-170

28. F. Hochhauser, W. Ernst, R. Rauch, R. Vallant, and N. Enzinger, Influence of the Soft Zone on the Strength of Welded Modern HSLA Steels, Weld. World, 2012, 56(5-6), p 77-85
29. M. Braunovic and N. Aleksandrov, Intermetallic Compounds at Aluminium-to-Copper and Copper-to-Tin Electrical Interfaces, Proceedings of the Thirty-Eighth IEEE Holm Conference on Electrical Contacts, 1992

30. M. Abbasi, A. Karimi Taheri, and M.T. Salehi, Growth Rate of Intermetallic Compounds in $\mathrm{Al} / \mathrm{Cu}$ Bimetal Produced by Cold Roll Welding Process, J. Alloys Compd., 2001, 319(1-2), p 233-241 